\title{
European Union
}

\section{"GS Media"}

\section{Decision of the European Court of Justice (Second Chamber) 8 September 2016 - Case No. C-160/15}

\author{
GS Media BV v. Sanoma Media Netherlands BV, \\ Playboy Enterprises International Inc., and Britt \\ Geertruida Dekker
}

Directive 2001/29/EC, Art. 3(1)

(C) Max Planck Institute for Innovation and Competition, Munich 2017

Keywords Communication to the public · Hyperlinks · Financial gain - Illegal nature of online publication . Presumption of knowledge $\cdot$ Consent

Article 3(1) of Directive 2001/29/EC of the European Parliament and of the Council of 22 May 2001 on the harmonization of certain aspects of copyright and related rights in the information society must be interpreted as meaning that, in order to establish whether the fact of posting, on a website, hyperlinks to protected works, which are freely available on another website without the consent of the copyright holder, constitutes a 'communication to the public' within the meaning of that provision, it is to be determined whether those links are provided without the pursuit of financial gain by a person who did not know or could not reasonably have known the illegal nature of the publication of those works on that other website or whether, on the contrary, those links are provided for such a purpose, a situation in which that knowledge must be presumed. 